$\left[\begin{array}{l}\text { J. Soc. Cosmet. Chem. Jpn. } \\ \text { 文 }\end{array}\right.$

$\left[\begin{array}{lrr}\text { 報 } \\ 27(4) & 597-603 & (1994)\end{array}\right]$

\title{
香りの生理心理反応へのカオス時系列解析の応用
}

\author{
谷沢茂治 $\dagger^{1}$ ，木村知史 $\dagger^{1} ，$ 合原一幸 $\dagger^{2}$ \\ ポーラ化成工業株式会社研究所 肌科学研究室 ${ }^{1}$ \\ 東京大学 工学部計数工学科 ${ }^{2}$
}

\section{Application of Chaotic Time Series Analyses on Psychophysiological Responses to Odors}

\author{
Shigeharu Tanizawa $\dagger^{1}$, Satoshi Kimura $\uparrow^{1}$ and Kazuyuki Aihara $\dagger^{2}$ \\ POLA Laboratories, POLA Corporation. $\dagger^{1}$ \\ Faculty of Engineering, University of Tokyo. $\dagger^{2}$
}

\begin{abstract}
It is well-known that human biological systems produce chaotic behaviors such as rhythms of heart beat and plethysmograph. Odors are known to influence the psychophysiological state of a person, and produce fluctuations in plethysmographs regulated by autonomic system. In this study, we attempted to establish an index of psychophysiological responses induced by odors, using a feature of the chaotic behavior in plethysmograph. Such index could be extremely valuable in a research to characterize odors according to their responses in relation to human emotion.

We first confirmed the chaotic nature of the time-series data of plethysmographs. Correlation dimension, which reflects the chaotic characteristic of self-similarity in the plethysmograph, was estimated by the Grassberger-Procaccia method. Also investigated were relationships among correlation dimensions, physiological and psychological parameters including: 1) effects on correlation dimension of plethysmograph caused by changes in mental states when a pleasant or unpleasant odor is introduced, 2) relationships among psychological index and physiological parameters such as galvanic skin resistance and power spectrum of plethysmograph, 3) effects of physiological parameters on correlation dimension.

The results showed that: 1) correlation dimensions increased when unpleasant odor was introduced, 2) pleasant and unpleasant odors produced differences in galvanic skin resistance and power spectrum, 3) correlation dimension correlated with low-frequency component and ratio of power spectral components related to pleasure, displeasure and anxiety involved in emotion. It is concluded that the correlation dimension is sensitive to different odors and may be used as a reliable physiological index of pleasure and displeasure.
\end{abstract}

\section{1. 緒言}

良い香りを嗅げば気分が良くなり，悪い匂いを

$\dagger^{1} \overline{\mathbf{T}} 221$ 横浜市神奈川区高島台 27-1; 27-1, Takashimadai, Kanagawa-ku, Yokohama, 221 Japan

$\dagger^{2}$ T113 文京区本郷7-3-1; 7-3-1, Hongo, Bunkyoku, Tokyo 113 Japan
嗅げば不快な気分になることから，香りが私たち の感情や生理に影響を与えていることは明らかで ある。

香りの人に対する機能を裏付けるために, 脳波, 心拍数, 脈波や皮膚電位などの非侵襲的な生理計 測が多面的に行なわれている。しかし，脳波など の中枢系の計測では被験者への負担が大きく，脈 
波や皮膚電位などの末梢系の自律神経機能の計測 ではそれらの指標間で一致した変化を示さないこ とや再現性が悪いなどの問題点が指摘されてい る。

最近になって，人の体の中には心臓の拍動や指 尖容積脈波のリズムのように, カオス的挙動を示 す現象があることが分かってきた ${ }^{1) \sim 4 。 コ ゙ ー ル ト ゙ ~}$ バーガーは, 人の心臓の拍動りズムはカオス的な 変化をしているが, 重症の心疾患にかかった患者 では周期的なパターンを示すことを報告した1。 フリーマンらは鬼の嗅覚系に执いて, カオス的な 神経興奮パターンとその嗅覚認識に和ける機能に ついて調べた ${ }^{2)}$ 。さらに，佐光らは心血管系パラ メータ3)の, 津田らは指尖脈波 ${ }^{2)}$ のカオス性につ いて検討した。

これらのことから，カオスは生体の循環系や匂 いと深い関係があると考えることができる。ま た, 指尖容積脈波の波形が緊張—リラックスなど の心理状態によって変化し，その周波数成分と心 理状態の快一不快（不安との間に関係があること が報告されている(5) 。そこで指尖容積脈波がカ オスであるならば, そのカオス的挙動の特徴を捕 らえることにより, 香りに対する人の情動の生理 心理反応の新規な指標となることが期待される。

本報告は, 人の指尖容積脈波はカオスであるこ と, および香り刺激に対する脈波応答の相関次元 が心理状態の快一不快の生理指標として有効であ ること, についての可能性を確認したものであ る。

\section{2. 実験}

健常な女性10名（20 52歳, 平均年齢29歳）に 対し Fig.-1 のような手順に従い, 10 分間安静 後, 匂い呈示前後にブランク（旬いなし）を設定 し，好きな香り(レモンとバニラより本人が選択） および嫌いな匂い(トリェチルアミン)を各 3 分 ずつ呈示した。

匂いの呈示順序は，好き $\rightarrow$ 嫌いと嫌い $\rightarrow$ 好きの 各半数ずつとした。

\section{1 計測項目}

心理評価は, 匂い呈示前と呈示中の覚醒感, 快 不快感および勾いに対する嘫好性について, SD 法を用いて 5 段階で行った。生理計測は指尖容積 脈波, 呼吸特よび GSR の項目について連続して 行った。

\section{2 計測条件}

被験者は室温 $23 \sim 24^{\circ} \mathrm{C}$ のシールドルームで, 座位・開眼状態において計測した。

指尖容積脈波（左手第三指末節より時定数 DC で誘導）は日本電気三栄製ポリグラフと脈拍ピッ クアップ (45261), 呼吸 (腹部より誘導) は日本 電気三栄製呼吸ピックアップ（45261）, GSR（皮 膚電気抵抗：右手第二と三指末節より通電法で誘 導) は OG 技研製 BF-102 で測定し，これらの データはソニー製デジタルデータレコーダーPC$108 \mathrm{M}$ に記録した。

\section{3 生理パラメータ}

生理計測の指尖容積脈波から, フラクタル次元 の一つの尺度である相関次元, パワースペクトル procedure

$\mathrm{t}$ i m e

c ondition

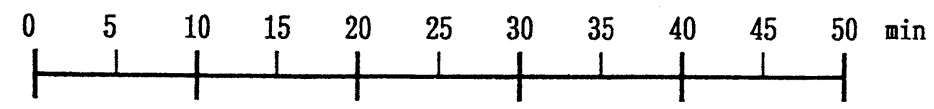

Rest
Blank Odor
Blank Odor
Blank

\section{menta 1 as s s sment}

$\uparrow \uparrow$

$\uparrow \uparrow$

$\uparrow$

Fig.-1 Experimental Procedure subject : 10 normal females with ages from 19 to 50 (average 29) measurement : plethysmogram, galvanic skin resistance, respiration 
の低周波成分 ( $\mathrm{LF}: 0.30 \mathrm{~Hz}$ 以下) と高周波成分 ( $\mathrm{HF}: 0.31 \mathrm{~Hz}$ 以上) 抽よびその周波数成分比 (Ratio : $\mathrm{R}=\mathrm{LF} / \mathrm{HF}$ ) の 4 項目のパラメータを 設定した。

\subsection{1 指尖容積脈波の相関次元}

自然界の海岸線や生体の血管などの図形は，そ の一部を拡大しても全体と同じような形を示す自 己相似性という性質を持っている。カオスの特徵 の一つであるこの幾何学的性質を定量的に示す相 関次元は，以下の方法により求める。

観測した指尖容積脈波を $\mathrm{A} / \mathrm{D}$ 変換によってサ ンプリング間隔が $20 \mathrm{~ms}$ になるような 1 変数の時 系列データに変換する。その自己相関関数が最初 に0 になる時刻より時間遅れ（lag）を求める。次 にアトラクタの軌道を再構成8) するために, 時系 列データ $\left(\mathrm{x}_{1}, \mathrm{x}_{2}, \cdots \cdots, \mathrm{x}_{\mathrm{t}}\right)$ から時間遅れ座標を 用いて $\mathrm{n}$ 次元べクトル $\left(\mathrm{X}_{1}, \mathrm{X}_{2}, \cdots \cdots, \mathrm{X}_{\mathrm{N}}\right)$ を作 成する。Grassberger-Procaccia の方法に従っ て(1)式より相関積分 $\mathrm{C}^{\mathrm{n}}(\mathbf{r})$ を計算し，(2)または (3)式のスケーリング側が近似的に成り立つ相関指 数 $\mathrm{D}(\mathrm{n})$ を求める ${ }^{9)}$ 。再構成空間の次元 $\mathrm{n}$ の増大 飞伴う $\mathrm{D}(\mathrm{n})$ の飽和值がフラクタル次元の一つの 近似值である相関次元を与兄る。相関次元の解析 はデータ数 : N=1000 (20秒間) で行い, 総合解 析には 1 分間の相関次元の平均值を使用した。

$$
\mathrm{C}^{\mathrm{n}}(\mathrm{r})=\lim \left(1 / \mathrm{N}^{2}\right) \sum_{\mathrm{i}, \mathrm{j}=1}^{\mathrm{N}} \mathrm{H}\left(\mathrm{r}-\left|\mathbf{X}_{\mathrm{i}}-\mathbf{X}_{\mathbf{j}}\right|\right)
$$

$\mathrm{H}$ : ヘビサイド関数, $\mathrm{r}$ : 半径,

$\mathrm{N}$ : データ数

$\mathrm{C}^{\mathrm{n}}(\mathrm{r}) \infty \mathrm{r}^{\mathrm{D}(\mathrm{n})}$

$\log \mathrm{C}^{\mathrm{n}}(\mathrm{r})$ vs $\mathrm{D}(\mathrm{n}) \log (\mathrm{r})$

\section{4 カオス特性の評価}

時系列データがカオスであることは，自己相似 性, 軌道不安定性および長期予測不能性の 3 つの 性質,すなわち各々フラクタル次元, リアプノフ指 数および $\mathrm{KS}$ エントロピーで評価される。リアプ ノフ指数の計算は佐野一沢田の方法で求めた ${ }^{10)}$ 。

\section{5 総合解析}

手の動きによるノイズの混入した 1名を除き，
9 名について解析を行った。

解析は匂い呈示中の心理価值や生理パラメータ の変動を確認し，匂い呈示後20～80秒の 1 分間の データを解析対象範囲とした。パラメータの絶対 值とブランク（匂い呈示前）に対するパラメータ の変化について，心理評価別抢よび匂いの種類別 に $\mathrm{t}$ 一検定叔よび相関分析を行った。

\section{3. 結果と考察}

\section{1 指尖容積脈波のカオス特性の確認}

指尖容積脈波よりの時系列データがカオスであ れば，その時系列データから再構成した $\mathrm{n}$ 次元べ クトルのアトラクタ (Fig.-2) が自己相似性, 軌 道不安定性拈よび長期予測不能性の 3 つの性質を 有している。それらはフラクタル次元が非整数で あること, リアプノフ指数と KS エントロピーが 共に正であることで原理的には確認できる。実際 に, ブランクやトリェチルアミンで，相関次元は $2 \sim 3$ の非整数值, リアプノフ指数は正の值を示 した (Table-1)。

これによって，観測された指尖容積脈数の時系 列データがカオスであることが示唆され，津田 ${ }^{4)}$ らの結果が確認された。
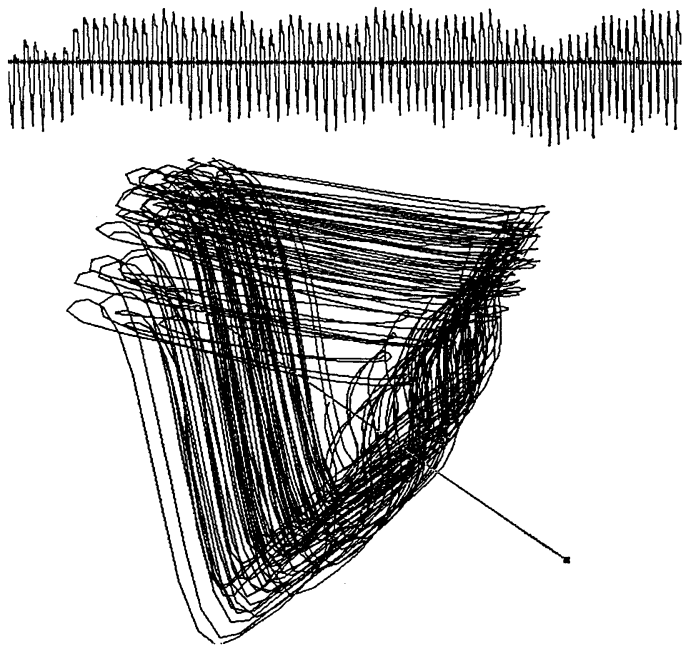

Fig.-2 An attractor in a 3-dimensional phase space reconstructed from plethysmograph 


\section{粧 技 誌 第27巻第 4 号 1994}

Table-1 Characterization of plethysmograph from the viewpoint of chaotic time series analyses

\begin{tabular}{|c|c|c|c|}
\hline $\begin{array}{l}\text { chaotic } \\
\text { characteristic }\end{array}$ & measure & $\begin{array}{l}\text { (in the case of } \\
\text { deterministic chaos) }\end{array}$ & $\begin{array}{l}\text { It on plethysmograph } \\
\text { blank \& amine } \\
\text { (upper) (lower) }\end{array}$ \\
\hline self & correlation & (noninteger) & 2.61 \\
\hline similarity & dimension & & 2.75 \\
\hline orbital & Lyapunov & (positive) & +0.068 \\
\hline instability & exponent & & +0.079 \\
\hline
\end{tabular}

このことは，指尖容積脈波が少数自由度の非線 形的なダイナミクスによって支配され，自己相似 的な構造を伴なら変動を繰り返し，軌道不安定な 時系列変化を生じていることを示唆している。そ して，観測した指尖容積脈波の時系列データょり 再構成したアトラクタの自己相似構造の幾何学的 および力学的な定量值である相関次元和よびリア プノフ指数が, 指尖容積脈波の時系列データの解 析に利用可能になる。実際に匂いを嗅いだ時に, その種類や人によって指尖容積脈波の時間的な変 化は多少なりとも異なる傾向を示した。そこでこ れらのカオスの特性值によって, 人の情動の生理 心理反応を定量的に捉えることが期待される。

\section{2 相関次元解析法の検討}

1 回の相関次元の計算を行らための最適な時間 範囲を検討した結果を Fig.-3 に示す。
図は数值微分により求めた $\operatorname{Slope}\left(\log \mathrm{C}^{\mathrm{n}}(\mathrm{r}) /\right.$ $\log (r))$ vs $\log (r)$ の関係を示している。20秒 間の条件では $\log (\mathrm{r})$ に対してほぼ一定の Slope を示し，信頼性の高い相関次元を求めることがで きた。このことは，指尖容積脈波は20秒位ずつの 定常性を維持しながら変動することを示唆してい る。

相関次元を求める Grassberger-Procaccia の相関積分法は，脳波のような実験データではそ のデータ数，時間ずらし，サンプリング時間およ びノイズなどによって相関次元が全く異なった り，信頼性が之しいことが報告されている11)。本 解析では Grassberger-Procaccia の相関積分 法において, 埋め达み次元に対して時間遅れを変 化させる Rapp らの方法を用いて ${ }^{12)}$ ，Fig.-3に 示すような比較的信頼性の高い相関次元を得るこ

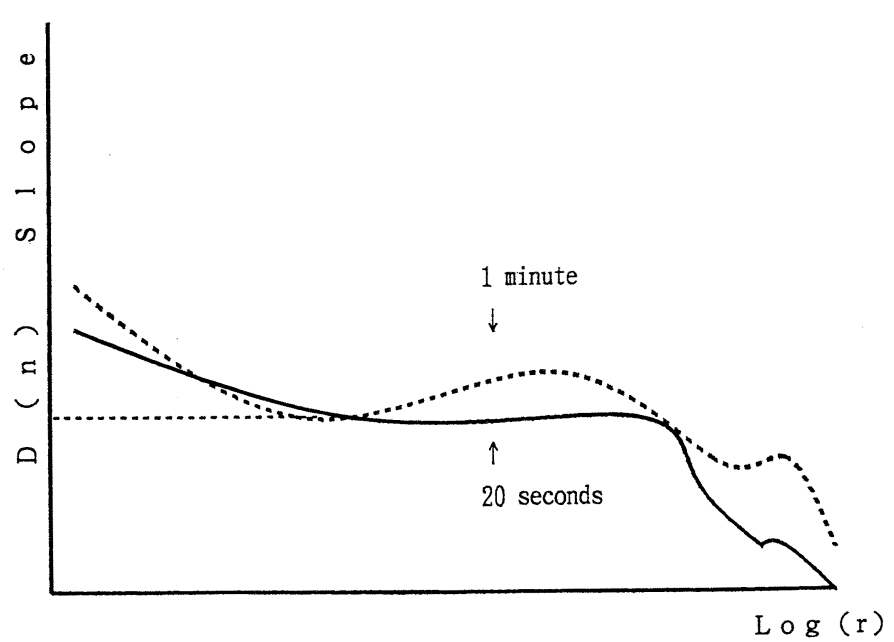

Fig.-3 Effect of the time range on correlation dimension 
とを可能にした。

その条件で，匂いを嗅いだ時の相関次元の経時 変動の 1 例を Fig. -4 に示す。

レモンを㖵いでいる時とトリェチルアミンを嗅 いでいる時の両者の間には, 相関次元のレベルの 違いが認められ, 被験者 9 名中 8 名でトリエチル アミンが高い傾向を示した。この結果, 匂いによ
って相関次元が異なる可能性が示された。

\section{3 嗜好別・快不快別による相関次元への影}

\section{響}

匂いによる心理評価の暂好および快不快別の相 関次元への影響を Fig.-5 に示す。

嗜好別では全被験者がレモンをやや好き以上， トリェチルアミンをやや嫌い以上と評価し, 嗜好

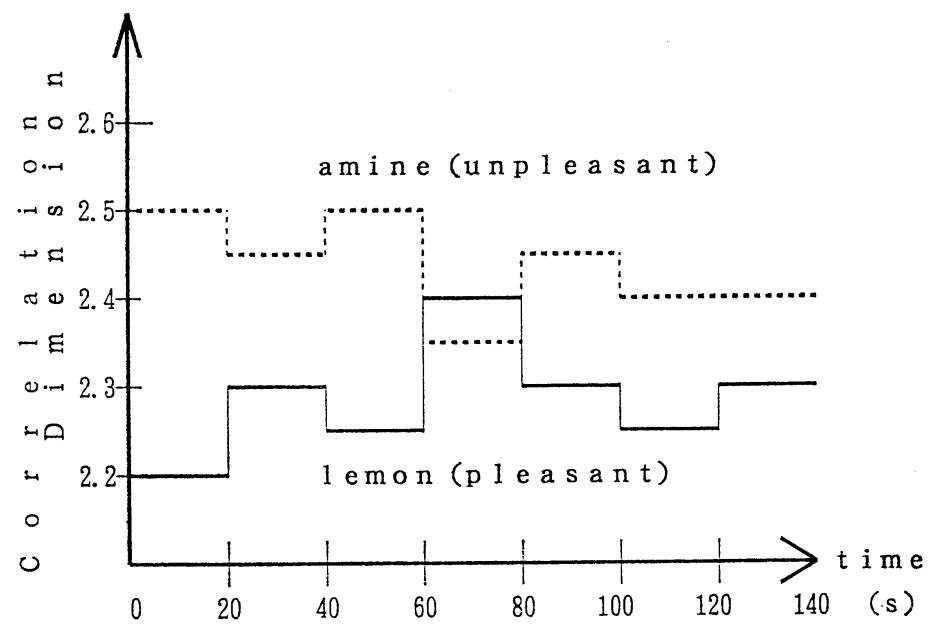

Fig.-4 Temporal changes of correlation dimension caused by odors

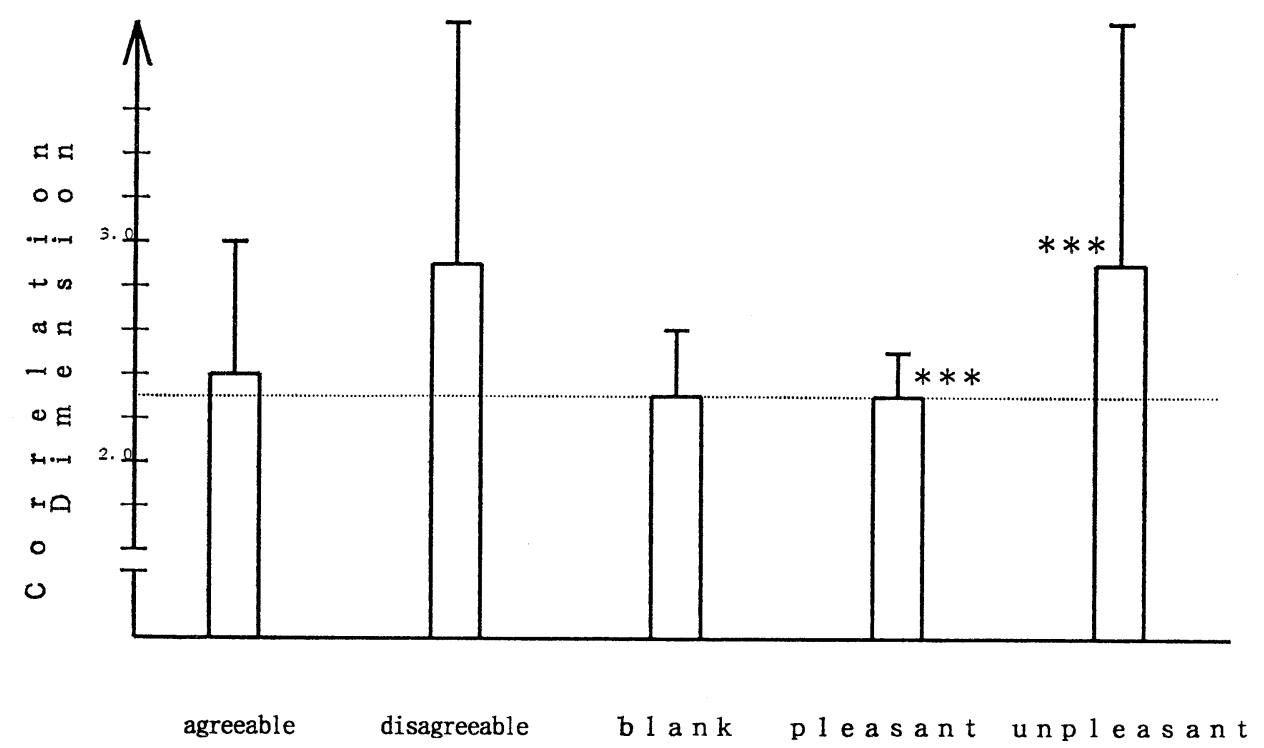

Fig.-5 Effects of mental states on correlation dimension $* * *: \mathrm{P}<0.001$ 


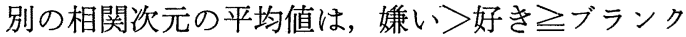
の傾向を示した。レモンのよらな香りに対しては 好きであっても快と評価しない被験者がいた。そ こでやや快以上のように 5 段階評価の 4 以上や 2 以下の評価を行った被験者を同一のグループと し，心理状態の快と不快のグループに分けて相関 次元の平均值を比較すると, 両者の間に有意な差 を認めた。また，相関次元の変化 $(\Delta \mathrm{D}$; 直前のブ ランクに対する相関次元の差）について嗜好別と 快不快別に比較すると，不快の場合は相関次元の 上昇が大きく，快と不快では有意な差を認めた。 この結果は相関次元が心理状態の快不快と関係す ることを示唆した。

\section{4 嗜好別・快不快別による生理パラメータ への影響}

箸好別・快不快別のグループのその他の生理パ ラメータへの影響を Table-2 に示す。

匂いに対して好きと嫌いのグループ間牞よび快 と不快のグループ間で，指尖容積脈波の低周波成 分 LF およびその周波数成分比 Ratio は有意な 差を認めた。また，ブランクからの変化でも同様 のグループ間で低周波成分 LF 拈よび GSR は有 意な差を認めた。

山崎らは指尖容積脈波の周波数解析を行い，そ
の LF や Ratio が不安などの情動と関係するこ とを示唆し5) 7)，堀川らは GSR で安らぎ効果を 評価している ${ }^{13)}$ 。

今回の句いの実験もこれらの報告と同様に，心 理の快不快に対応した生理パラメータの変化を確 認した。

\section{5 相関次元と心理・生理パラメータとの関 係}

生理パラメータと心理指標との相関関係を Table-3 に示す。

相関次元と心理評価の快不快感扤よび生理パラ ×ー夕の低周波成分 LF と周波数成分比 Ratio との間に有意な相関関係を認めた。この相関分析 扣よび先の相関次元の平均値の $\mathrm{t}$-検定より, 相 関 次元が心理状態の快不快感と関係し，心理状態の 不快度を示す新しい生理指標の可能性が示唆され た。

最近, 佐光らは姿勢による心血管系パラメータ のゆらぎへの影響を検討し，カオスの存在および 姿勢により相関次元が異なることを確認した ${ }^{14) 。 ~}$ さらに，心臓血管系のモデルシミュレーションを 行い，交感神経や副交感神経などの自律神経間の 複雑な非線形相互作用によって心拍リズムがカオ ス挙動を示し，その相関次元が変動することを推

Table-2 Effects of mental states on physiological parameters

\begin{tabular}{ccccccc}
\hline \hline psychological index & LF & HF & Ratio & Respiration & $\Delta$ GSR & $\Delta$ LF \\
\hline agreeable vs disagreeable & $*$ & n.s. & $*$ & n. s. & $* *$ & $*$ \\
pleasant vs unpleasant & $*$ & n.s. & $* *$ & n.s. & $*$ & $*$ \\
\hline
\end{tabular}

** $: \mathrm{P}<0.01, *: \mathrm{P}<0.05$ n. s. no significance

Table-3 Relationships among psychological and physiological parameters

\begin{tabular}{lcccccc}
\hline \hline parameters & dimension & pleasant & likes & LF & HF & Ratio \\
\hline correlation dimension & - & $*$ & n. s. & $*$ & n.s. & $* *$ \\
pleasant and unpleasant & & - & $* *$ & $* *$ & n.s. & $* *$ \\
likes and dislikes & & & - & n. s. & n.s. & $* *$ \\
LF & & & & - & n. s. & $* *$ \\
HF & & & & - & $* *$ \\
Ratio (LF/HF) & & & & & - \\
\hline
\end{tabular}

** : $\mathrm{P}<0.01, *: \mathrm{P}<0.05$, n. s. no significance 
察した ${ }^{3)}$ 。こことから，指尖容積脈波における 相関次元も自律神経機能と密接な関係があり, ト リエチルアミンのような嫌いな刺激によって不快 や不安が増加し, 交感神経系の働きが強まるなど のより複雑な自律神経の調節が行われ, 相関次元 が増加したものと考兄られる。今回はカオス時系 列解析法の開発と応用のために，2 種類の匂いで 検討を行った。今後, 香りの種類を増やして検討 を進めることによって, 相関次元等のカオスの指 標の意味とその定量性が確認できるものと考えら れる。

\section{4. 総 括}

匂いによって引き起こされる人の情動の生理心 理反応の評価に，カオス時系解析法を適用した。 観測した指尖容積波より得た時系列データがカオ スであることを確認し，カオス特性值の一つであ る相関次元と心理指標拉よび生理パラメータとの 相互関係を解析した。その結果, 相関次元が匂い による人の快不快と関係があり，匂いに影響され る不快の生理指標として有効であることが示唆さ れた。

終わりに本研究のリアプノフ指数などのカオス 解析に関して, 有益な助言とご指導をいただきま した東京理科大学基礎工学部の池口徹先生に感謝 の意を表します。

\section{引用文献}

1) A. L. Goldberger and B. J. West, Ann. NY. Acad. Sci., 504, 195 (1987)

2) C. A. Skarda and W. J. Freeman, Behavioral and Brain Sciences, 10(2), 161 (1987)

3) 佐光興覀, 横井博之, 第 7 回生体生理工学シンポ ジウム論文集, p .475 (1992)

4) I. Tsuda, T. Tahara and H. Iwanaga, Int. J. Bifurcation and Chaos, 2, 313 (1992)

5) K. Yamazaki, The Japanese Journal of Psychology, 53, 2, 102-106 (1982)

6) A. Murata, The Japanese Journal of Ergonomics, 28, 206 (1992)

7）中沢恒幸, 心身医, 27, 1, 82 (1987)

8) F. Takens, Lecture Notes in Mathematics 898, 366, Springer (1981)

9) P. Grassberger and I. Procaccia, Physica, 9D, 189 (1983)

10) M. Sano and Y. Sawada, Phys. Rev. Lett., 55, 10, 1082 (1985)

11）西藤聖二ら, 信学技報, NLP 88-54, 1 (1988)

12) P. E. Rapp, A. M. Albano and A. I. Mees, "Dynamic Patterns in Complex Systems", p. 191 (1988) World Sciertific, Singapore.

13）堀川壽夫, J. Soc. Cosmet. Chem. Japan., 18, 1, 26 (1984)

14) 佐光興亜, 横井博之, 第 6 回生体生理工学シンポ ジウム論文集, p .381 (1991)

（1993年 9 月16日受理） 